\title{
Hashimoto Encephalopathy: Advanced Review of Clinical and Scientific Aspects
}

\author{
Valeriy Zvonarev ${ }^{1, *}$, and Polina Tregubenko \\ ${ }^{1}$ School of Behavioral Sciences, California Southern University, Costa Mesa, United States \\ ${ }^{2}$ Internal Medicine Residency Program, Jacobi Medical Center, Albert Einstein College of Medicine, Bronx, NY
}

*Corresponding author: Valeriy Zvonarev, School of Behavioral Sciences, California Southern University, Costa Mesa, United States, Tel: +16263897415; E-mail: zvonarevval@gmail.com

Received: 09 Jan, 2020 | Accepted: 29 Jan, 2020 | Published: 06 Feb, 2020

Citation: Zvonarev V, Tregubenko P (2020) Hashimoto Encephalopathy: Advanced Review of Clinical and Scientific Aspects. J Neurol Neurobiol 6(1): dx.doi.org/10.16966/2379-7150.159

Copyright: ( 2020 Zvonarev V, et al. This is an open-access article distributed under the terms of the Creative Commons Attribution License, which permits unrestricted use, distribution, and reproduction in any medium, provided the original author and source are credited.

\section{Introduction}

Hashimoto encephalopathy (HE), also known as SteroidResponsive Encephalopathy associated with Autoimmune Thyroiditis (SREAT), appears to be a form of encephalopathy that develops against the background of an increased level of antibodies; complications such as brain tumors, stroke or infection of the central nervous system have not been observed. Although the incidence of HE is relatively low, there have been reports of patient deaths and the development of status epilepticus as a result of the given pathology. This makes the earliest possible start of therapy critical issues, especially since the overwhelming majority of patients respond positively to corticosteroid therapy.

However, diagnosis of HE is difficult due to its non-specific clinical features and a wide range of symptoms, including alterations in behavior, delusions, and hallucinations-exclusion of encephalopathies associated with cognitive impairments, autoimmune encephalitis, prion disease, as well as other neurological pathologies is required before a diagnosis can be made.

In this regard, further HE studies and the identification of new specific diagnostic criteria for this disease remain a relevant direction in modern medicine.

The purpose of this article is to provide an integrated, synthesized overview of the current state of knowledge and outline the scope of the topic. Specifically, this review focuses on the definitions, pathogenesis and treatment of HE. We also review the currently available therapies and approaches to treat $\mathrm{HE}$ as well as the scientific and clinical data that support their effectiveness.

Due to the infancy of research in this area, the reasons for the relationship between thyroid dysfunction and autoimmune encephalitis remain unclear. Further analysis is required to support the hypothesis that a high level of serum anti-TPO (anti-thyroid peroxidase) antibodies increases the chances of suffering from neuropsychiatric symptoms. Clinical studies with novel therapeutics, antibodies, and different signal transduction inhibitors demonstrate their clinical activity in various autoimmune encephalitides, however, it remains unclear how to successfully integrate novel agents either alone or in combination with steroids into the overall schema for HE.

\section{Hashimoto encephalopathy epidemiology}

At present, Hashimoto encephalopathy (HE) is defined as a syndrome of encephalopathy and high serum anti-thyroid antibody concentrations that reacts to glucocorticoid therapy. The first case of HE was described in 1966 and was associated with hallucinations, tremors, exaltation, altered mental status and elevated antibody levels against the thyroid gland. In this case, the diagnosis of $\mathrm{HE}$ was confirmed after establishing the Hashimoto autoimmune thyroiditis diagnosis based on the thyroid biopsy results. As of 2017, more than 200 cases of HE have been reported. In most cases, patients respond well to therapy but serious clinical manifestations such as status epilepticus and three fatal outcomes have been reported [1].

It is necessary to mention that some specialists will not consider $\mathrm{HE}$ to be an independent nosological unit until definitive evidence is obtained that antibodies against thyroid antigens really do cause encephalitis [2].

Chong JY, et al. analyzed articles in the MEDLINE database published before June 2002 and identified 85 patients with encephalopathy and high level of anti-thyroid antibodies in their blood serum; at the onset of disease, the average patient age was 44 years old (with a range from 9 to 78 years old) [3]. Clinical features of patients with HE is presented in Table 1.

According to the latest estimates, the frequency of $\mathrm{HE}$ is 2.1:100,000, with predominance in women in the $5^{\text {th }}$ to $6^{\text {th }}$ decades of life. The reported sex ratio for this disease is 4.1 in favor of women, and $\mathrm{HE}$ is less common in children than in adults [1].

Within the pediatric population, the average age of disease onset is 14 years; it should also be noted that the majority of pediatric patients are female. About $30 \mathrm{HE}$ cases in children and adolescents were 
Table 1: Clinical features of patients with Hashimoto Encephalopathy.*

\begin{tabular}{|c|c|c|c|c|c|}
\hline Feature & $\begin{array}{l}\text { Normal Thyroid } \\
\text { Function }(n=19)\end{array}$ & $\begin{array}{l}\text { Normal Thyroid Function } \\
\text { With Levothyroxine } \\
\text { Sodium Therapy }(n=7)\end{array}$ & $\begin{array}{c}\text { Subclinical } \\
\text { Hypothyroidism }(n=30)\end{array}$ & $\begin{array}{c}\text { Overt } \\
\text { Hypothyroidism } \\
(n=17)\end{array}$ & Allt(n=80) \\
\hline Female & $12(63)$ & $7(100)$ & $25(83)$ & $15(88)$ & $69(81)$ \\
\hline Age, mean (range), y & $45(14-73)$ & $30(12-70)$ & $48(12-78)$ & $41(12-76)$ & $44(9-78)$ \\
\hline Focal deficit & $7(37)$ & $3(43)$ & $6(20)$ & $4(24)$ & $23(27)$ \\
\hline Seizures & $10(53)$ & $6(86)$ & $21(70)$ & $12(71)$ & $56(66)$ \\
\hline Myoclonus & $6(32)$ & $4(57)$ & $15(50)$ & $3(18)$ & $32(38)$ \\
\hline Psychosis & $8(42)$ & $2(29)$ & $12(40)$ & $4(24)$ & $31(36)$ \\
\hline $\begin{array}{l}\text { Relapsing-remitting } \\
\text { course }\end{array}$ & $12(63)$ & $6(86)$ & $14(47)$ & $11(65)$ & $51(60)$ \\
\hline $\begin{array}{l}\text { High CSF protein } \\
\text { concentration }\end{array}$ & $13(68)$ & $4(57)$ & $25(83)$ & $14(82)$ & $66(78)$ \\
\hline $\begin{array}{l}\text { Abnormal imaging } \\
\text { findings }\end{array}$ & $9(47)$ & $3(43)$ & $17(57)$ & $8(47)$ & $40 / 82(49)$ \\
\hline Abnormal EEG findings & $17 / 18(94)$ & $7(100)$ & $28(93)$ & $16 / 16(100)$ & $80 / 82(98)$ \\
\hline $\begin{array}{l}\text { Response to } \\
\text { glucocorticoid therapy }\end{array}$ & $\begin{array}{c}16 / 18(89) \\
(1 \text { not treated })\end{array}$ & $7(100)$ & $\begin{array}{c}22 / 23(96) \\
(7 \text { not treated) }\end{array}$ & $\begin{array}{c}12 / 12(100) \\
(5 \text { not treated) }\end{array}$ & $\begin{array}{c}67 / 70(96) \\
(15 \text { not reated })\end{array}$ \\
\hline Goiter & $4 / 8(50)$ & $6 / 6(100)$ & $4 / 5(80)$ & $3 / 5(60)$ & $24 / 39(62)$ \\
\hline Serum anti-M present & $13 / 14(93)$ & $5 / 5(100)$ & $18 / 19(95)$ & $10 / 10(100)$ & $55 / 58(95)$ \\
\hline Serum anti-TPO present & $4 / 4(100)$ & $3 / 3(100)$ & $10 / 10(100)$ & $7 / 7(100)$ & $26 / 26(100)$ \\
\hline Serum anti-Tg present & $8 / 14(57)$ & $4 / 4(100)$ & $17 / 21(81)$ & $8 / 13(62)$ & 45/62 (73) \\
\hline
\end{tabular}

Abbreviations: Anti-M- anti-thyroid microsomal antibody; anti-TPO- anti-thyroid peroxidase antibody; anti-Tg- antithyroglobulin antibody; CSFcerebrospinal fluid; EEG- Electroencephalography

*Data are given as number (percentage) except where indicated otherwise.

tIncluding all thyroid abnormalities or unknown thyroid status.

described in the literature in 2014; the youngest HE case was in a girl aged 2 years and 10 months [4].

The vast majority of patients with HE, regardless of gender and age, are characterized by thyroid function deficiency without distinct clinical manifestations (subclinical hypothyroidism). Quite often, cases of patients with a euthyroid status, including those against the background of hormone replacement therapy, are reported. At the same time, a case of HE was described in a 39-year-old woman where neurological symptoms started to appear 3 years earlier than the thyroiditis diagnosis was made [5]. Statistical data on the possible interrelationship of $\mathrm{HE}$ and thyroid gland functional status are presented in figure 1.

The main clinical manifestations of HE include convulsions such as myoclonus, psychotic phenomena and stroke-like symptoms. An equally wide range of the HE clinical manifestations is seen in children (behavioral and cognitive alterations, epileptic myoclonus, convulsions, involuntary movements, psychosis, and coma) [4].

Imaging and laboratory tests reveal alterations in EEG, changes in brain structures on MRI, increases in the level of protein in the cerebrospinal fluid (CSF) and an increase in the level of autoimmune antibodies, primarily against TPO and thyroid gland cells. Statistical data on the frequency of the main symptoms of HE are presented in table 2 .

When using glucocorticoid therapy, according to statistical data, a decrease in convulsion intensity or the complete disappearance thereof was observed in $66 \%$ of patients, epileptic myoclonus in $48 \%$, psychotic phenomena in $43 \%$, protein level normalization in the CSF in $77 \%$ of patients, brain structure normalization (according to MRI data) in $47 \%$ and EEG pattern normalization in $98 \%$ of patients [3].

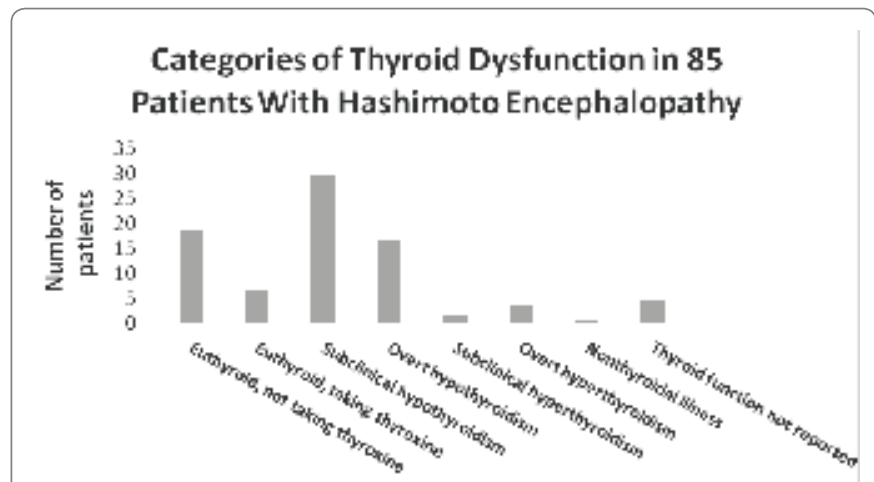

Figure 1: Association of HE with thyroid gland functional status [3].

Thus, according to the statistical data presented in the literature, HE is a rare disease that is found much more frequently in adult women and is associated with thyroid gland function disorder. HE indicators are very diverse, both in manifestation and severity (from insignificant cognitive disorders to generalized convulsions and coma). HE clinical manifestations in adults and children are generally similar: cognitive disorders and convulsions are predominant. The vast majority of HE patients respond well to therapy with corticosteroids, which quickly and effectively improve the patient's condition and prevent the occurrence of further relapses.

\section{Literature Review}

\section{HE pathogenesis}

Traditionally, HE is considered to be an autoimmune disease, taking 
Table 2: Frequency of occurrence of the main symptoms of $\mathrm{HE}$.

\begin{tabular}{|l|c|c|}
\hline & $\begin{array}{c}\text { Chong JY, et al. (2003) } \\
{[3]}\end{array}$ & $\begin{array}{c}\text { Tang Y, et al. (2012) } \\
\text { [6] }\end{array}$ \\
\hline Sample characteristics & $\begin{array}{c}\text { Clinical cases from the } \\
\text { Medline database until } \\
\text { June 2002 }\end{array}$ & $\begin{array}{c}\text { HE patients } \\
\text { diagnosed from 2005 } \\
\text { to 2010 in the Suan } \\
\text { hospital (Beijing) }\end{array}$ \\
\hline Number of patients & 85 & 13 \\
\hline Stroke-like characters & $27 \%$ & $23.1 \%$ \\
\hline Seizures & $66 \%$ & $30.8 \%$ \\
\hline Myoclonus & $38 \%$ & $7.7 \%$ \\
\hline Status epilepticus & $12 \%$ & $10 \%$ \\
\hline Psychiatric symptoms & $38 \%$ & $38.5 \%$ \\
\hline Cognitive disorders & Not available & $84.6 \%$ \\
\hline $\begin{array}{l}\text { Protein level increase } \\
\text { in CSF }\end{array}$ & $78 \%$ & $61.5 \%$ \\
\hline EEG pattern alteration & $98 \%$ & $40 \%$ \\
\hline MRI picture alteration & $49 \%$ & $46.2 \%$ \\
\hline $\begin{array}{l}\text { Increase in antibodies } \\
\text { level against } \\
\text { thyroglobulin }\end{array}$ & Not available & Not available \\
\hline Disease recurrence & $60 \%$ & \begin{tabular}{c}
$13 \%$ \\
\hline
\end{tabular} \\
\hline
\end{tabular}

into account its close correlation with the level of auto antibodies that interact with thyroid gland antigens, as well as its satisfactory response to steroid therapy $[7,8]$. Antibodies against thyroid peroxidase (TPO) were not identified in the cerebrospinal fluid of patients with HE. These antibodies could enter into autoimmune reactions with brain neurons and vascular cells leading to vasculitis or damage to brain cells [9]. The identification of other pathogenic auto antibodies and immune complexes was also reported in HE patients [10].

Ferracci et al., who was the first to describe HE, believed that focal symptoms observed in his patient were determined by cerebral edema; cerebral edema could also explain the rapid response to steroids. This hypothesis had a large number of supporters, who suggested that acute symptoms of $\mathrm{HE}$ are based on vasogenic edema, similar to the acute disseminated encephalomyelitis (ADEM). The cause of cerebral edema could be an autoimmune attack on major proteins of the myelin sheath, which leads to the development of cerebral vasculitis [11].

Evidence was obtained that HE could be induced by inflammation, which is indicated by the signs of perivascular lymphocytic inflammation identified in brain tissue samples from some patients with HE [12,13]. It is possible that inflammation in the CNS (probably caused by antibodies and neuronal protein binding) could be the main mechanism causing encephalopathy. This is indicated by the results of histopathological studies demonstrating the presence of arteriole and venule lymphocytic infiltration in the brain parenchyma and leptomeningeal tissues [14]. A posthumous pathological examination of tissues from a patient with HE carried out by Duffey and co-authors subsequently revealed lymphocytic infiltration around the venules and arterioles (Figure 2). The given phenomenon was observed in almost all brain divisions including the cortex, white matter, basal ganglia, and brainstem. Staining with specific antibodies demonstrated that lymphocytes were predominantly represented by T-cells [15].

The cerebral hypoperfusion hypothesis, as one of the HE pathogenic mechanisms, is also under discussion. The basis for hypoperfusion could lie in the brain microvasculature disorder caused by auto antibodies or immune complexes, as seen in the case of glomerulonephritis. However, the results of Single-Photon Emission Computed Tomography (SPECT) do not allow this hypothesis to be unambiguously accepted since some patients were observed with distinct signs of hypoperfusion [16], while others showed no evidence of this [9].

Since the euthyroid status (including against the background of thyroxin intake) reported in many HE clinical cases was typical for patients (Table 3), a number of experts emphasize the fact that HE is not determined by a deficiency in thyroid hormones (myxedema madness), but is an independent phenomenon [17]. In addition, in hyperthyroid encephalopathy, EEG would be characterized by the accelerated alpha rhythm, rather than generalized or focal slowdown, as seen in the case of $\mathrm{HE}$ and similar encephalopathies [5].

Lymphocytes surrounding small venula in the brain of a deceased patient with HE. Hematoxylin, eosin, Luxol blue. Scale segment is 100 $\mu \mathrm{m}$ (Drulović J, et al. [18]) (Figure 2).

At the same time, an opinion was expressed that the distinct excess or deficiency of thyroid hormones could cause metabolic states that exacerbate cerebral cortex instability and enforce both neurological and psychiatric manifestations of HE. It is known that neuropsychiatric disorders (confused consciousness, psychosis, convulsions, and manic and depressive mood alterations) could also be observed in hyperthyroidism without HE; also, similar conditions could be significantly improved by normalizing thyroid function [19]. In addition, there are data showing an association of autoimmune thyroid gland disease and progressive cerebellar degeneration in adults, which primarily manifests itself in the form of ataxia [20]. Despite the lack of evidence confirming that there is a direct cause and effect relationship between $\mathrm{HE}$ and thyroid gland diseases, experts always recommend considering the possibility of a subclinical autoimmune thyroid gland disease in a patient suffering from unexplained recurrent episodes of myoclonia, generalized convulsions, focal neurological disorders or psychogenic disorders [5].

In addition to the autoimmune mechanisms associated with the circulation of antibodies against thyroid gland antigens, the increased secretion of thyroid-releasing hormone (TRH) is also being discussed as a probable pathophysiological factor of HE. Accordingly, patients receiving thyroxine, which suppresses the secretion of TRH and TSH via a negative feedback loop, demonstrate attenuation in the symptomatology of HE [5].

In the last decade, the possible involvement of FAS receptors in the pathogenesis of HE has come under discussion. This explains the efficacy of immunoglobulin implementation in treating HE since immunoglobulins contribute to the destruction of cells expressing FAS receptors on their surface. It is assumed that FAS-mediated processes are involved in the development of HE by the induction of apoptosis at the site of inflammation. Consequently, it could be assumed that the apoptotic mechanisms involved in the initiation of thyroiditis could also lead to the progression of encephalopathy if a patient possesses prerequisites for this.

In general, specialists unanimously assign a decisive role in the pathogenesis of HE to the autoimmune component. Autoimmune reactions create the basis for disseminated encephalomyelitis and/or autoimmune generalized cerebral vasculitis, which cause a wide range of symptoms and abnormalities resulting from the brain blood supply and metabolism abnormalities. Thus, another possible mechanism of HE pathogenesis could be auto antibodies promoting demyelination 


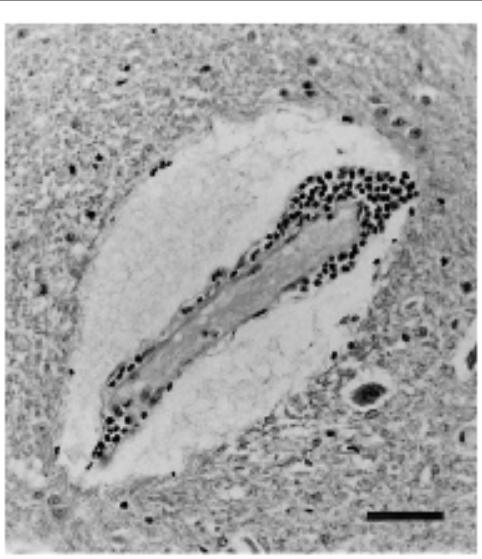

Figure 2: Lymphocytes surrounding small venula in the brain of a deceased patient with HE. Hematoxylin, eosin, Luxol blue. Scale segment is $100 \mu \mathrm{m}$ (Drulović J, et al. [18]).
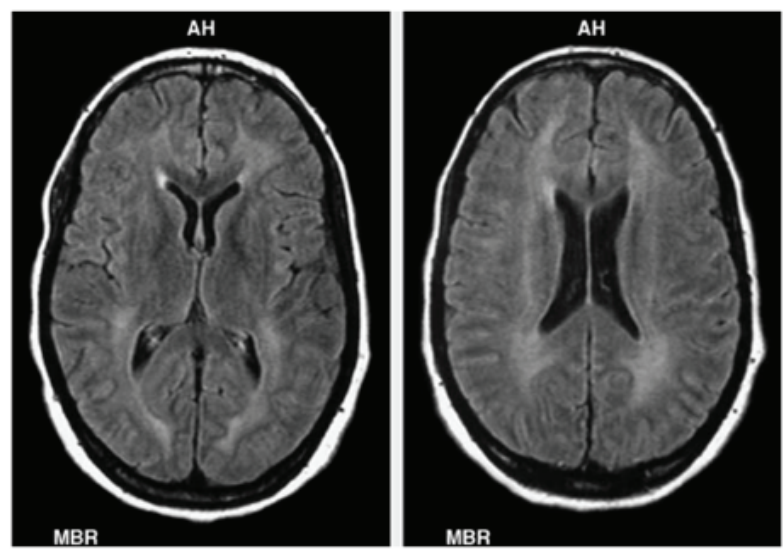

Figure 3: MRI identification of periventricular alteration in white matter in patient with $\mathrm{HE}$. Slices at the level of the basal ganglia and at the level of the corona radiata are presented [17].

processes in the central nervous system. In particular, a patient with an established diagnosis of HE was described, whose ataxia, cognitive functions disorder and peripheral demyelination were characterized by the same deterioration, improvement and remission dynamics [21].

As already noted, with almost all patients, $\mathrm{HE}$ is associated with increased levels of antibodies against TPO.

Additionally, there is an increased level of antibodies against thyroglobulin and, in several cases, antibodies against the thyrotropin receptor. Moreover, antibodies against thyroid cells were often detected directly in the cerebrospinal fluid of patients with HE. It is important to note that the antibody level decreases in parallel with the clinical improvement in patient condition [22].

Hypothyroidism is accepted as a widespread autoimmune condition. According to some data, about $10 \%$ of the adult populations have elevated levels of certain auto antibodies against thyroid gland antigens, while $3-4 \%$ of the populations have a diagnosis of autoimmune thyroiditis. On the contrary, $\mathrm{HE}$ is a rare clinical manifestation, even taking into account possible undiagnosed cases. These statistics indicate that other provoking factors besides the

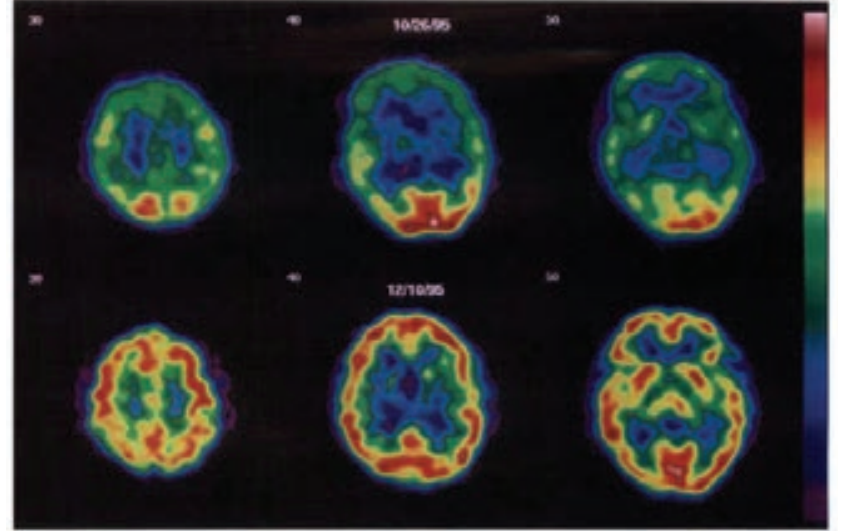

Figure 4: Brain SPECT 90 minutes after injecting the technetiumlabeled hexamethylpropyleneamine.

presence of anti-thyroid antibodies could become a characteristic feature for HE patients [23].

Several years ago, a new autoimmune antigen, the alpha-enolase amino-terminal fragment (NAE), was detected in the brain of HE patients, along with high levels of antibodies against this antigen, while no such antibodies were found in patients with other neurological diseases [23].

It could be assumed that several other types of auto antibodies that were relatively recently discovered in HE patients also play an important role in the pathogenesis of this disease. Thus, antineuronal antibodies were detected in the blood serum of two HE patients; these antibodies reacted with the $36 \mathrm{kDa}$ molecular weight protein present in the soluble fraction obtained from the human cerebral cortex. It is not impossible that these auto antibodies are also associated with the pathogenesis of HE. Immunoglobulins interacting with certain enzymes in the human CNS, such as dimethylargininase-I and two aldehyde reductase-I isoforms, were also detected in the cerebrospinal fluid of patients with HE. Normally, these enzymes are widely represented in the endothelial brain vessel cells and neurons. Accordingly, an autoimmune response directed against these enzymes could lead to damage to vessels and/or neurons, which remain the two major pathogenic targets in the case of HE [22].

It could be concluded that the detailed pathogenetic pattern of HE remains unknown, largely due to extremely diverse clinical manifestations, but the most probable mechanisms are brain vasculitis and autoimmune reactions directed against the total brain and thyroid gland antigens.

\section{Clinical features}

HE is characterized by a wide range of symptoms that include behavioral alterations, confused consciousness, decreased cognitive abilities, stroke-like episodes, amnesia syndrome, ataxia [24], convulsions including myoclonic seizures and mental disorders [25]. Separate cases of chorea were described in patients with HE [26]. However, this aspect of disease could vary significantly with different patients (Table 3 ), which essentially complicates the diagnosis process.

The disease could manifest clinically as various combinations of symptoms that might disappear, recur or alternate; also, new 
Table 3: HE clinical aspect polymorphism (separate clinical cases of HE randomly selected and described by different authors are presented).

\begin{tabular}{|c|c|c|c|c|}
\hline No. & Sex and age & Clinical symptoms & Laboratory findings & Source \\
\hline 1 & $\begin{array}{l}\text { Male, } \\
47 \text { years }\end{array}$ & $\begin{array}{c}\text { Tremor of upper extremities, unsteady gait, falls, } \\
\text { generalized attack, coma, then delirium, memory } \\
\text { deterioration, and visual hallucinations, problems } \\
\text { with speech }\end{array}$ & $\begin{array}{l}\text { Contrast CT-without pathology; retarded EEG without epileptic } \\
\text { activity; normal CSF pressure, increased protein content in } \\
\text { CSF; increased level of anti-microsomal and anti-thyroglobulin } \\
\text { antibodies, euthyroid status }\end{array}$ & Boers P, et al. [27] \\
\hline 2 & $\begin{array}{l}\text { Female, } \\
17 \text { years }\end{array}$ & $\begin{array}{l}\text { Partial and generalized convulsions, tremor, } \\
\text { coma, Hashimoto thyroiditis, disorientation in } \\
\text { time and space, confused consciousness }\end{array}$ & $\begin{array}{l}\text { Increased levels of anti-TPO; MRI-without pathology; EEG- } \\
\text { slow-wave frontal activity }\end{array}$ & Cantón A, et al. [28] \\
\hline 3 & $\begin{array}{l}\text { Female, } \\
47 \text { years }\end{array}$ & $\begin{array}{l}\text { Generalized convulsions, monoclonal tremor, } \\
\text { coma, Hashimoto thyroiditis }\end{array}$ & $\begin{array}{l}\text { Elevated levels of thyroid gland hormones and antibodies } \\
\text { against TPO and thyroglobulin, MRI-without pathology; EEG- } \\
\text { generalized slowing }\end{array}$ & Cantón A, et al. [28] \\
\hline 4 & $\begin{array}{l}\text { Female, } \\
21 \text { year }\end{array}$ & $\begin{array}{c}\text { Generalized convulsions, tremor, coma, Graves } \\
\text { disease }\end{array}$ & $\begin{array}{l}\text { Elevated level of antibodies against TPO and thyroglobulin, } \\
\text { euthyroid status; MRI - without pathology; EEG - generalized } \\
\text { slowing, euthyroid status with patient receiving thyroxin }\end{array}$ & Cantón A, et al. [28] \\
\hline 5 & $\begin{array}{l}\text { Female, } \\
54 \text { years }\end{array}$ & $\begin{array}{c}\text { Problems with speech, standing instability, } \\
\text { diffuse postural tremor, confused consciousness } \\
\text { and hallucinations, ataxia }\end{array}$ & $\begin{array}{l}\text { EEG-moderate diffusive slowing(in delta and theta ranges); } \\
\text { MRI-increased signal intensity in the periventricular white } \\
\text { matter; increased protein content; sharp increase in anti- } \\
\text { microsomal antibodies; euthyroid status with patient receiving } \\
\text { levothyroxine }\end{array}$ & Cao NJ, et al. [17] \\
\hline 6 & $\begin{array}{l}\text { Female, } \\
63 \text { years }\end{array}$ & $\begin{array}{c}\text { Memory deterioration, headache, ataxia; in a } \\
\text { few months, deterioration of cognitive functions, } \\
\text { tremor, generalized convulsions }\end{array}$ & $\begin{array}{c}\text { MRI-increase in the signal intensity from white matter in } \\
\text { the zone of posterior fossa and deep gray nuclei; subclinical } \\
\text { hypothyroidism; increased level of antibodies against } \\
\text { microsomes and thyroid gland; brain biopsy- perivascular } \\
\text { lymphocyte infiltration }\end{array}$ & $\begin{array}{l}\text { Chong JY, } \\
\text { et al. [3] }\end{array}$ \\
\hline 7 & $\begin{array}{l}\text { Female, } \\
38 \text { years }\end{array}$ & $\begin{array}{l}\text { Paresthesia, gait instability, headaches, } \\
\text { Hashimoto thyroiditis }\end{array}$ & $\begin{array}{l}\text { Initial CT, MRI and EEG- without pathology; euthyroid status } \\
\text { against the background of hormone replacement therapy; CSF } \\
\text { - normal protein and lymphocytes levels; increased levels of } \\
\text { antibodies against TPO, antibodies against thyroglobulin were } \\
\text { not detected; two years after treatment with steroids - non- } \\
\text { specific changes in the EEG }\end{array}$ & $\begin{array}{l}\text { Drulović J, } \\
\text { et al. [18] }\end{array}$ \\
\hline 8 & $\begin{array}{l}\text { Male, } \\
40 \text { years }\end{array}$ & $\begin{array}{l}\text { Generalized tonic and clonic convulsions, } \\
\text { involuntary hand movements, cognitive } \\
\text { disorders, coma }\end{array}$ & $\begin{array}{c}\text { Hypothyroidism; elevated level of antibodies against TPO } \\
\text { including those in CSF; CSF-elevated protein level; CT-without } \\
\text { pathology; EEG-bifrontal commissures and high-frequency } \\
\text { wave activity }\end{array}$ & $\begin{array}{l}\text { Duffey } P \text {, } \\
\text { et al. [15] }\end{array}$ \\
\hline 9 & $\begin{array}{l}\text { Female, } \\
75 \text { years }\end{array}$ & $\begin{array}{l}\text { Confusion, gait instability, temporary loss } \\
\text { of consciousness, falling; a few days later, } \\
\text { spontaneous recovery }\end{array}$ & $\begin{array}{c}\text { Euthyroid status against the background of taking thyroxin; } \\
\text { EEG-generalized slowing; MRI and CT-without pathology; } \\
\text { increased level of antibodies against TPO and thyroglobulin, } \\
\text { including those in CSF }\end{array}$ & $\begin{array}{l}\text { Ferracci F, } \\
\text { et al. [29] }\end{array}$ \\
\hline 10 & $\begin{array}{l}\text { Female, } \\
67 \text { years }\end{array}$ & $\begin{array}{l}\text { Progressive psychomotor inhibition, tendency to } \\
\text { fall, ataxia }\end{array}$ & $\begin{array}{l}\text { Euthyroid goiter; EEG-diffused synchronous slowing; CT and } \\
\text { MRI-without pathology; increased level of antibodies against } \\
\text { TPO and thyroglobulin, including those in CSF }\end{array}$ & $\begin{array}{l}\text { Ferracci F, } \\
\text { et al. [29] }\end{array}$ \\
\hline 11 & $\begin{array}{l}\text { Female, } \\
28 \text { years }\end{array}$ & $\begin{array}{c}\text { Complaints of fatigue, myoclonic convulsions, } \\
\text { memory deterioration }\end{array}$ & $\begin{array}{l}\text { Hashimoto thyroiditis; MRI and EEG-without pathology; CSF- } \\
\text { normal; elevated levels of antibodies against thyroglobulin in } \\
\text { blood plasma }\end{array}$ & $\begin{array}{l}\text { Spiegel J, } \\
\text { et al. [30] }\end{array}$ \\
\hline 12 & $\begin{array}{l}\text { Male, } \\
55 \text { years }\end{array}$ & $\begin{array}{l}\text { Loss of memory, decreased concentration, } \\
\text { myoclonic convulsions }\end{array}$ & $\begin{array}{l}\text { MRI-without pathology; EEG-diffused slowing; CSF-increased } \\
\text { protein levels; increased level of antibodies against TPO in } \\
\text { blood and CSF }\end{array}$ & $\begin{array}{l}\text { Spiegel J, } \\
\text { et al. [30] }\end{array}$ \\
\hline 13 & $\begin{array}{l}\text { Male, } \\
66 \text { years }\end{array}$ & $\begin{array}{c}\text { Memory impairment, progressive problems } \\
\text { with speech, dizziness, fluctuating awareness, } \\
\text { balance problems, apraxia, twitching of the } \\
\text { upper and lower extremities, mood changes, and } \\
\text { hallucinations }\end{array}$ & $\begin{array}{l}\text { The neuropsychological examination described a cognitive profile } \\
\text { with a dysexecutive/subcortical picture. MRI - without pathology. } \\
\text { Chest X-ray and full-body-PET - no signs of extra-cerebral } \\
\text { malignancy. Brain FDG-PET - decreased global cortical glucose } \\
\text { metabolism. Negative biomarkers for Alzheimer's dementia } \\
\text { (Aß42, F-tau; P-tau) in the cerebrospinal fluid, but elevated levels } \\
\text { of both protein and leukocytes. Elevated anti-TG }\end{array}$ & $\begin{array}{l}\text { Lagström RMB, et } \\
\text { al. [31] }\end{array}$ \\
\hline 14 & $\begin{array}{l}\text { Female, } \\
21 \text { year old }\end{array}$ & $\begin{array}{c}\text { Presented with hiccuping for } 1 \text { month, urinary } \\
\text { retention, gait instability, and weakness of limbs } \\
\text { accompanied with dyspnea for } 2 \text { days. Behavioral } \\
\text { changes, eg. self-talking behavior, paranoid ideas, } \\
\text { incoherent speech, persecutory delusions, auditory } \\
\text { hallucinations, and disorientation in time and space. } \\
\text { Dysarthria, nystagmus, weakened extremities and } \\
\text { increased DTRs bilaterally }\end{array}$ & $\begin{array}{l}\text { EEG-widespread slowing of background activity without sharp } \\
\text { waves. MRI without changes. CSF showed the concentration } \\
\text { of protein to be } 0.4 \mathrm{~g} / \mathrm{L} \text { and cell count of } 5 \times 106 \text {. High } \\
\text { concentrations of antithyroid antibodies }\end{array}$ & $\begin{array}{l}\text { Sharma SR. } \\
\text { et al. [32] }\end{array}$ \\
\hline
\end{tabular}

Citation: Zvonarev V, Tregubenko P (2020) Hashimoto Encephalopathy: Advanced Review of Clinical and Scientific Aspects. J Neurol Neurobiol 
symptoms could be added over time. In addition, HE may not be a monosymptomatic disease and could cause more than just mental disorders, progressive myelopathy, dementia, paresthesia attacks or cerebellar symptoms [11].

In some cases, HE suddenly starts in the form of attacks of strokelike or confused consciousness states and is not always accompanied by other neurological signs. In other cases, the disease develops gradually in a remitting pattern, with progressive cognitive deterioration and psychiatric symptoms [18].

A clinical case described by Ferlazzo E, et al. can be presented as an example of the probable development of HE. A 41-year-old man experienced three episodes of generalized convulsions in a period of 9 months. CSF analysis revealed an elevated protein level $(89 \mathrm{mg} /$ dL) accompanied by a normal cell amount and glucose level. Blood serum and CSF microbiological tests produced negative results. Brain MRI with the introduction of gadolinium indicated no pathology. The patient was prescribed phenobarbital $(100 \mathrm{mg} /$ day $)$ but experienced another attack of generalized convulsions after five months, which was preceded by drowsiness, irritability, and tremors throughout the whole week. Over the next 40 days, episodes of spatial disorientation associated with drowsiness, tremor and gait disorders recurred. Four months later, the patient experienced the third episode of convulsions which was not controlled by diazepam and stopped only as a result of thiopental infusion. Three days later, thiopental was stopped, but the patient remained in a coma for the following four days. After exiting the coma, constant diffuse slowing without epileptic activity was observed on the EEG. A neurological examination indicated mild drowsiness, gait ataxia, and tremor. Neuropsychological assesment revealed abnormal verbal functions. Studies of the functional state of the thyroid gland revealed hypothyroidism against the background of an increased thyroid-stimulating hormone level and decreased level of thyroxine. Also, high levels of antibodies against thyroid gland antigens were reported: antibodies against thyroid peroxidase, microsomes, and thyroglobulin. The patient's condition spontaneously improved within 2 weeks, including normalization in his neurological and neuropsychological status, as well as an improvement in EEG pattern. Hormone-replacement therapy was prescribed (thyroxin, 75 $\mathrm{mcg}$ ); the patient refused treatment with steroids. After two weeks, he again experienced difficulties finding words, as well as tremor and gait instability; during neurological examination, myoclonic movements of the head and hands were also identified. Neuropsychological assesment revealed serious abnormalities in fluency of speech, as well as minor abnormalities in computational abilities and verbal memory. EEG demonstrated moderate slowing in both temporal areas and myoclonic reaction to intermittent photo stimulation. CT showed a moderate decrease in blood flow in the frontal areas. On the third day, the patient experienced an attack accompanied by clonic movements of his right hand, followed by a generalized tonic-clonic convulsion. After that, methylprednisolone was administered intravenously for 5 days. Within 5 days the patient's condition improved significantly. Neurological and neuropsychological indicators, as well as the EEG pattern, returned to normal. During the 12-month follow-up observation period (against the background of taking $50 \mathrm{mg} /$ day methylprednisolone and $100 \mathrm{mcg} / \mathrm{day}$ levothyroxine), the patient no longer experienced relapses and did not complain of any symptoms [33].

A case history published by Forchetti CM, et al. could be considered as an example of the combination of psychopathological and neurological symptoms of HE [16]. A 59-year-old woman was admitted for examination in regard to progressive dementia. Her family first noticed mental alterations while on a vacation about 5 months before the admission. Those changes consisted of a somewhat depressed mood and slightly reduced fluency of speech and activity. A month later, her colleagues at work (the patient was working as a nursing assistant) noted apathy, an inability to recall work schedules and official duties and a decrease in productivity. Immediately before admission to the hospital, the patient was recommended to take leave from work due to memory disorders and instability. Family members noted that she was becoming increasingly embarrassed, and the quality of her speech and understanding of what was happening was deteriorating. Brain MRI, echocardiogram, and Dopplerography of the carotid arteries showed normal results. TSI was elevated; CSF results were normal, with the exception of increased protein levels. Ultrasound examination of the thyroid gland revealed a diffuse hypoechoic gland. The patient started taking sertraline to treat depression and levothyroxine as a hormone replacement therapy. During a new examination following referral to neurology, her speech was fluent, but she had difficulties with finding words. She hardly remembered her age and date of birth, and did not manage to solve the tasks of sequential subtraction. Her hands trembled when writing, but she was able to copy drawings. A motor examination revealed nonpermanent tremor, minimal at rest, and unchanged plantar reactions. The CSF analysis again showed elevated levels of protein, but the rest of the studied parameters were normal. Brain MRI demonstrated mild generalized atrophy, while brain SPECT indicated a total decrease in perfusion. EEG showed diffuse slowing of background activity. Furthermore, a marked decrease in all cognitive functions, primarily disorders in attention, concentration and memory, was observed; also, distinct myoclonus in all extremities and increased tremor was noted. The patient was not able to execute two-step commands, could not speak in sentences and was hallucinating. However, a month after hormone replacement therapy (without corticosteroid therapy), her family reported an improvement. Improvements in her mental and neurological status were confirmed during examinations including MRI, brain SPECT and EEG, and results thereof were within the normal range [16].

In some cases, psychopathological symptoms predominate, while neurological symptoms are represented only by separate transient episodes. Another example published in work by Rodriguez AJ, et al. [34] should also be considered. A 56-year-old woman was admitted to the hospital in an acute confused mental state. The anamnesis contained hypothyroidism, hypertension and migraine, but examination revealed only confused speech. MRI results were normal. CSF analysis revealed only a moderate increase in protein level. EEG showed a general slowing from 6 to $7 \mathrm{~Hz}$ without focal disorders. Further examination demonstrated normal thyroid gland functioning against the background of an increase in antibodies against TPO. The patient's mental state normalized spontaneously during the night, and she was discharged from the hospital. A week later, the patient again experienced an acute confused mental state and general aphasia of moderate degree. The MRI was not changed, and CSF analysis showed elevated protein. EEG revealed a generalized slowing and decrease in amplitude in the left hemisphere. The patient was administered dexamethasone intravenously. Clinical improvement occurred during the night and correlated with an improvement in the EEG pattern. The patient was discharged, but a week later, she again encountered an acute confused mental state. Cerebral angiography showed no signs of vasculitis. During angiography, the patient experienced acute loss of speech function. Tomographic examination did not reveal any signs of acute ischemia or hemorrhage. EEG performed within 1 hour after the loss of speech demonstrated total slowing and a decrease in amplitude 
in the right hemisphere. The patient was intravenously injected with dexamethasone accompanied by continuous EEG monitoring. Mental status and aphasia normalized during the night, which correlated with the EEG normalization. The patient was discharged with a prescription of high doses of prednisone; no further relapses were reported [34].

Termsarasab P, et al. reported 21- and 40-year-old females who presented with autoimmune thyroiditis and subacute pure ataxia, but without encephalopathy. Upon completion of standardized immunotherapy, both patients exhibited initial improvement of ataxia, and subsequently remained in partial remission. Interestingly, pure ataxia without encephalopathy was diagnosed only in several cases. Authors concluded that it is crucial not to misdiagnose steroidresponsive encephalopathy associated with autoimmune thyroiditis with pure cerebellar ataxia [35].

Cognitive disorders (84.6\% of patients) and psychiatric symptoms (38.5\% of patients), including depression, mania, psychosis and hallucinations, are commonly encountered symptoms [25,36]. Subacute dementia with an inconspicuous invasion followed by the schizophrenic syndrome has been described in elderly patients with HE.

Cotard syndrome is a psychiatric syndrome reported in many disease states but publications on its association with $\mathrm{HE}$ are absent. Another case of a 44-year-old female who presented with the classical organic Cotard syndrome symptoms in association with vegetative, motor and cognitive signs was reported by Hajnal and Lazary. The increased serum anti-TPO, the non-specific MRI findings and the positive response to steroid therapy confirmed the diagnosis of HE [37].

Extra cerebral disorders are extremely rare in HE. A case of rigid extremities anti-GAD-negative syndrome associated with $\mathrm{HE}$ was described, as well as one case of granulomatous myositis associated with antibodies against anti-thyroglobin and TPO without encephalopathy. There were no reports of peripheral nerve involvement in the HE clinical picture [38].

The researchers in the Liu S, Ma Q and Zheng Y paper discussed the case study of the association of febrile HE with acute pancytopenia and Graves' disease; their subject presented with Graves' disease in addition to pancytopenia and fever. The patient presented with gait impairment, delirium, agitation and disorientation. MRI confirmed high signal white-matter and showed symmetrical subcortical high signal lesions on diffusion-weighted imaging and fluid-attenuated inversion recovery scans. The researchers, however, note that the signs and symptoms of HE have a varied presentation and could be divided into two subtypes: diffuse progressive and vasculitis. They also concluded that HE may occur in various thyroid states such as euthyroidism and may mimic meningitis or thyroid storm [39].

Characteristic features of the clinical manifestations of $\mathrm{HE}$ in children were analyzed in detail in the work by Gayatri NA and Whitehouse WP, who showed that children also possess wide variation in the clinical picture of this disease. As with adults, acute attacks and encephalopathy were most commonly observed $(70 \%$ of children with $\mathrm{HE}$ ), as well as a decrease in cognitive abilities ( $40 \%$ of children with $\mathrm{HE}$ ). At the same time, tremor and myoclonus, which were usually present in adults with HE, were found in $12.5 \%$ of infant patients. As with adults, HE could develop in children against the background of euthyroid status or against the background of hypothyroidism to a lesser extent (hypothyroidism was detected with about $50 \%$ of children with HE). However, hyperthyroidism, which is sometimes found in adult patients with HE, was never observed in children with the same diagnosis. The EEG results for children with HE (as with adult patients) usually demonstrate the diffused slowing of rhythms [40].

\section{HE diagnostics}

Laboratory research: Antibody levels against thyroid gland cells and thyroid gland function: An increase in the level of antibodies against the thyroid gland, including anti-thyroglobulin or anti-TPO (antibodies against thyroid gland or thyroid peroxidase), is observed in most HE cases. An increase in the anti-TPO level is most typical of HE. A study of 105 patients with a diagnosis of HE showed that the level of antibodies against TPO was elevated in $100 \%$ of cases, and the level of antibodies against thyroglobulin was elevated in $48 \%$ of cases. Also, antibodies against thyroid-stimulating hormone (anti-TSH) were detected. It should be noted that the antibody titer against TPO in patients with $\mathrm{HE}$ is much higher than in patients with Hashimoto thyroiditis. However, the anti-thyroid antibody titer in plasma correlates poorly with the severity of $\mathrm{HE}$, and the increased level of antibodies against thyroid gland cells also persists after treatment [41].

In the context of HE diagnosis, it is necessary to pay attention to the fact that a high level of anti-thyroid antibodies in plasma was found in cancer patients who received Ipilimumab. An association of increased levels of anti-thyroid antibodies with hepatitis B and C, as well as with the Helicobacter pylori infection, was also described in patients with type 1 diabetes [1].

Magnetic resonance imaging (MRI) and computed tomography (CT): Most patients with HE are characterized by normal brain MRI results, although using MRI could identify pathological signs such as ischemic lesions, demyelination, edema and atrophy in some cases. Signs of pathology found in the hippocampus or temporal lobe are believed to be associated with loss of memory or paresthesia attacks in patients with HE [1]. Periventricular and diffuse alterations of white matter close to the brain ventricles were described in a patient with HE (Figure 3) [17]. In particular, cerebral atrophy, nonspecific subcortical focal anomaly of white substance, diffused subcortical anomaly, focal cortical anomaly and temporary bilateral narrowing of the middle cerebral artery were identified in patients with HE based on MRI results [3].

Recently discovered auto antibodies targeting the NH2-terminal of alpha-enolase (NAE) have been applied as useful diagnostic markers for HE. Matsunaga A, et al. attempted to dig deeper into longitudinal changes in MRIs in HE associated with the biomarker (anti-NAE antibodies). An investigation of 12 Japanese patient brain MRIs revealed multiple small subcortical abnormalities or non-specific lesions of the white matter in 10 subjects. In 7 subjects, fluctuating lesions of the white matter and the emergence of high-intensity subcortical spots with the use of diffusion-weighted images was evident with improvement on recovery and worsening on relapse. The authors concluded that the fluctuating MRI changes observed with $\mathrm{HE}$ associated with anti-NAE antibodies confirms the autoimmune pathophysiology of HE [42].

In a study using SPECT in patients with HE, areas of the brain tissue with reduced perfusion are detected relatively often (Figure 4). It is possible that the wider use of advanced neuroimaging options would ensure that new data on the pathogenesis of HE are obtained. Thus, using MRI spectroscopy showed a decrease in $\mathrm{N}$-acetylaspartate levels and an increase in the choline-containing compound level in the mesotemporal regions and anterior sections in a patient with HE [43].

SPECT images during the patient state deterioration (upper row) show increased activity in the occipital lobes on both sides 
against the background of markedly reduced perfusion of temporal, parietal and frontal lobes on both sides. SPECT images after clinical improvement in the patient condition (bottom row) demonstrate symmetrical distribution of the radiopharmaceutical preparation in brain and cerebellum hemispheres showing significant improvement in comparison with the previous study [16].

Cerebrospinal Fluid (CSF) composition: An increase in protein level in the cerebrospinal fluid (CSF) is found in $85 \%$ of patients with $\mathrm{HE}$ and is not decreased after treating the disease. An increase in the level of antibodies against the thyroid gland in the CSF is found in $62-75 \%$ of patients diagnosed with HE; it should be mentioned that elevated levels of these antibodies could persist even after the onset of clinical improvement. Since the increase in the level of anti-thyroid antibodies in the plasma possesses low specificity, as already noted, it is recommended to assess the level of anti-thyroid antibodies both in the patient's blood and CSF in order to establish the diagnosis of HE [1]. Increased protein levels in the CSF were observed in almost all patients with HE $[3,17]$.

EEG: The most common EEG abnormality is generalized slowing, the degree of which varies from medium to distinct; similar changes in the EEG have been observed in more than $95 \%$ of cases (Figure 5). EEG results reflect the extent of CNS damage and could be used to monitor the response to steroid therapy. In some patients, EEG could identify three-phase waves: epileptiform abnormalities, photomyogenic response and photoparoxysmal response [45].

Other biological markers: As already noted, amino-terminal of alpha-enolase (NAE) was identified in brain tissues of patients with

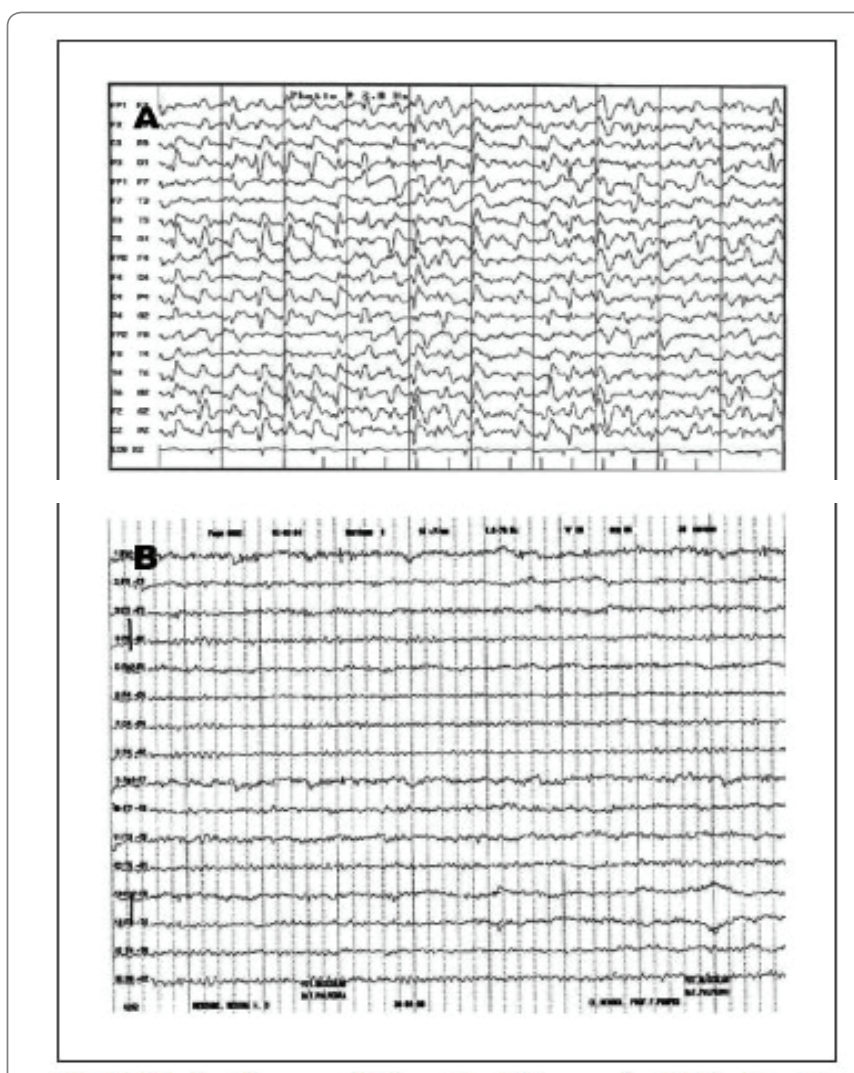

Figure 5: EEG of a 68-year-old patient diagnosed with HE. (A) At admission-presence of triphasic complexes. (B) After 2 months of treatment. EEG under normal variation values [44].
$\mathrm{HE}$, and the level of antibodies against NAE was increased in $68-83 \%$ of patients with an established diagnosis of HE. It should be emphasized that antibodies against NAE were not identified in patients with other neurological diseases, which demonstrates the high specificity of this indicator for HE. Antibodies against NAE along with anti-thyroid antibodies could serve as useful biological markers in HE diagnostics [46]. Using a marker in the CSF, such as 14-3-3 protein, remains subject to discussion; however, data on identifying the 14-3-3 protein in HE patients are being accumulated at present [47].

HE diagnostic criteria: At present, and according to expert opinion, it is impossible to unambiguously identify generally accepted HE diagnostic criteria due to the low prevalence of this disease, diversity in clinical manifestations and the lack of data regarding its basic pathogenic mechanisms; consequently, HE is a diagnosis of exclusion. The current generally accepted HE diagnostic criteria are presented in table 4 .

According to specialists, autoimmune encephalitis, i.e. a disease associated with antibodies against the N-methyl-D-aspartate receptor (NMDAR) and manifested by psychiatric symptoms with acute onset, is among the neurological diseases that should be initially excluded when making the diagnosis of HE [48]. It is also necessary to exclude probable CNS infections (including encephalitis and meningoencephalitis), inflammatory conditions such as systemic lupus and primary vasculitis of CNS and paraneoplastic limbic encephalitis, as well as brain tumors and stroke. HE is often initially diagnosed as a prion disease, for example, Creutzfeldt-Jakob disease [1].

\section{Therapy and prognosis}

The first-line therapy in the treatment of HE is corticosteroids. Prednisone is recommended (50-150 mg/day or $1-2 \mathrm{mg} / \mathrm{kg} /$ day). The literature also describes the use of methylprednisolone at high doses (500-1,000 mg/day) administered intravenously [8]. In about 50\% of cases, when using corticosteroids, the complete disappearance of clinical symptoms is reported; also, $40 \%$ of patients experience complete remission after the first course of corticosteroid therapy [49]. In some cases, psychiatric symptoms appear following steroid therapy; in this scenario, the dosage and duration of treatment with corticosteroids should be adjusted.

It is necessary to emphasize that, unlike adults, in adolescents with $\mathrm{HE}$, long-term complications of moderate severity can develop during therapy using corticosteroids. According to Vasconcellos E, et al. two children diagnosed with HE showed residual cognitive deficit after treatment with corticosteroids, and the other two developed recurrent attacks [50]. Erol I and co-workers did not observe any complications in children and adolescents following corticosteroid therapy; however, they indicated that it was impossible to make any long-term forecasts based upon a limited observation period (up to 5 years) [18]. In particular, repeated increases in the levels of antibodies against the thyroid could occur despite clinical improvement caused by steroid therapy [8].

In cases resistant to corticosteroids, immunosuppressants can be used in the treatment of HE. Patients resistant to corticosteroids are recommended to employ combined therapy using immunosuppressants such as azathioprine, cyclophosphamide and methotrexate [51]. Additional therapy with immunosuppressive preparations such as rituximab and monoclonal antibodies against CD20 has also demonstrated its efficacy in patients with manifestations of opsoclonus. In a recent review, the use of rituximab was reported in 7 out of 13 patients. There was complete or almost complete resolution of symptoms in all 7 patients, including those who had experienced

Citation: Zvonarev V, Tregubenko P (2020) Hashimoto Encephalopathy: Advanced Review of Clinical and Scientific Aspects. J Neurol Neurobiol 
Table 4: Main generally accepted HE diagnostic criteria.

\begin{tabular}{|c|c|c|c|}
\hline Clinical manifestations & Laboratory tests & Response to therapy & Exclusion of other diseases \\
\hline $\begin{array}{l}\text { Encephalopathy accompanied by regression of } \\
\text { cognitive function }\end{array}$ & \multirow{5}{*}{$\begin{array}{l}\text { High level } \\
\text { of anti-TPO } \\
\text { antibodies }\end{array}$} & \multirow{5}{*}{$\begin{array}{l}\text { Improvement in clinical } \\
\text { picture and restoration } \\
\text { of laboratory parameters } \\
\text { under corticosteroid } \\
\text { therapy }\end{array}$} & Exclusion of neurology diseases \\
\hline $\begin{array}{l}\text { Encephalopathy accompanied by psychiatric } \\
\text { symptoms }\end{array}$ & & & Exclusion of toxic damage to the nervous system \\
\hline $\begin{array}{l}\text { Encephalopathy accompanied by partial or } \\
\text { generalized convulsions }\end{array}$ & & & \multirow{3}{*}{$\begin{array}{c}\text { Exclusion of metabolic disorders affecting the } \\
\text { nervous system }\end{array}$} \\
\hline $\begin{array}{l}\text { Encephalopathy accompanied by focal } \\
\text { neurological pathology or consciousness } \\
\text { alteration }\end{array}$ & & & \\
\hline Encephalopathy accompanied by dystonia & & & \\
\hline
\end{tabular}

an incomplete response to other therapies. It was concluded that rituximab is well tolerated and usually results in long-term remission, without the need for long-term steroids [52].

Mattozzi S, et al. (2020) attempted to assess whether pretreatment criteria of HE predicts successful outcomes due to steroid therapy. They evaluated 24 patients for the symptoms and responsiveness to steroidal medications using preselected pretreatment criteria. Other studies included screening for TPOAb $(>200 \mathrm{IU} / \mathrm{mL})$ in 74 patients with possible autoimmune encephalitis (AE) and 205 patients with different neuropsychiatric disorders. Only $29 \%$ of the 24 patients identified were diagnosed with encephalopathy, while only $31.6 \%$ of these patients showed complete response to steroid therapy. They concluded that the currently available treatment criteria do not adequately predict the steroid therapy responsiveness in HE patients. The authors recommend methodically ruling out encephalitis mediated by antibodies in redefining HE [53].

Patientswhoareunabletotakecorticosteroidsorimmunosuppressants for one reason or another could use plasmapheresis [54]; in addition, the efficacy of using IV immunoglobulin has been demonstrated in both adults and children. There have also been separate reports on the efficacy of levetiracetam in patients with HE, but the use of this preparation requires further research [1].

In particular, the efficient use of plasmapheresis in a patient with HE was described by Boers and Colebatch [27]. A 47-year-old man was prescribed a course of plasmapheresis (four treatment procedures totaling 26.8 liters), in addition to prednisone and azathioprine to remove pathogenic antibodies. The patient's condition improved after the first plasmapheresis treatment procedure, and he could independently dress, eat and speak English after completing the course, and was even able to return to his work as a cleaner. That clinical improvement was accompanied by a decrease in the concentration of antibodies (Figure 6). When he subsequently suffered a new attack, three plasmapheresis treatment procedures (total volume of $21.0 \mathrm{l}$ ) again led to a decrease in the concentration of antibodies and clinical improvement [27].

A novel study sponsored by Seoul National University Hospital, evaluated the efficacy of erythropoietin in refractory autoimmune encephalitis. Ten patients received $100 \mathrm{IU} / \mathrm{kg}$ of erythropoietin 3 times a week for 12 weeks. It was suggested that erythropoietin can improve refractory autoimmune encephalitis due to tissue-protective effects via activation of Janus kinase (JAK)-2, the signal transducer and activator of transcription (STAT)-5 pathway and the NF-kappa B pathway. The results of this study will be published in 2020 [55].

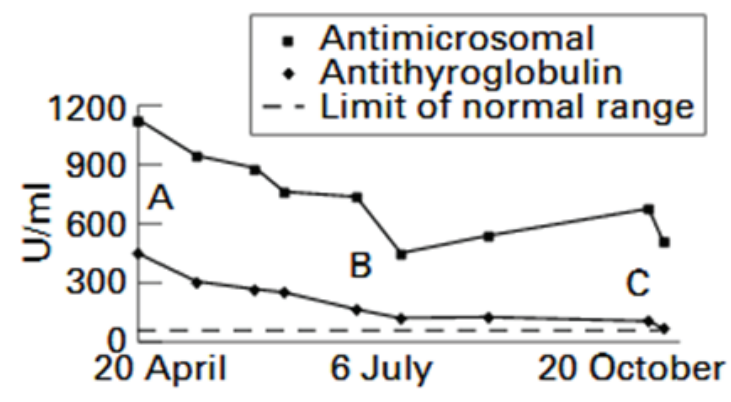

Figure 6: Anti-thyroid antibody level alterations after using plasmapheresis in a patient with HE. Upper curve-level of antimicrosomal antibodies, lower curve-level of antibodies against thyroglobulin, dotted line -physiological norm. Point A-start of therapy with corticosteroids and azathioprine, points B and C-execution of plasmapheresis courses [27].

\section{Conclusion and Findings}

According to the statistical data, HE is a rare disease that is more often seen in adult women and is associated with autoimmune thyroiditis.

The pathogenesis of HE remains the subject of active debate. Autoimmune reactions could create a basis for the development of vasculitis, cerebral circulation disturbance, brain edema and demyelination in the CNS. Indeed, almost all patients with HE were diagnosed with increased levels of antibodies against TPO and often with other auto antibodies against thyroid gland antigens and CNS tissues. However, the final interpretation of the pathogenesis of $\mathrm{HE}$ requires further research. It is possible that inflammation plays a definite role in the pathogenesis of HE, leading to lymphocytic infiltration of the brain vessels, or an increased level of thyroid-releasing hormone. This is characteristic of the state of hypothyroidism, which is often reported in patients with HE. However, despite a wide range of alternative hypotheses, most experts unanimously assign a crucial role to the autoimmune component in the pathogenesis of HE.

HE clinical manifestations in adults and children are generally similar; cognitive disorders and convulsions are predominant. In addition, HE could be a monosymptomatic disease and could cause only mental disorders, progressive myelopathy, dementia, paresthesia attacks or cerebellar symptoms. It should be noted that all of the abovementioned symptoms could be observed in cases of other neurological or psychiatric diseases. 
Determination of the level of antibodies against TPO in blood serum, as well as EEG analysis, could be considered the most specific HE diagnostic tests. Most HE patients have normal brain MRI results; however, in some cases, pathological signs such as ischemic lesions, demyelination, edema and atrophy could be identified using MRI. Increased protein levels in the CSF are observed in most patients with HE [56].

Corticosteroid therapy appears to be a specific treatment demonstrating high efficacy in most patients. It should be noted that HE may have progressive development in some cases, leading to severe neurological complications including generalized convulsions and coma; therefore, corticosteroid therapy should be started as soon as possible, especially if the patient has an increased level of antibodies against TPO.

In patients that are resistant to corticosteroids, immunosuppressants could be used, while anticonvulsant preparations could be used in those experiencing distinct convulsions. Also, IV immunoglobulin's administration and plasmapheresis have been shown to be effective in a few cases.

In conclusion, it is necessary to emphasize that HE diagnosis and therapy remain difficult for specialists, primarily due to the low incidence of this disease; therefore, the discussion of each new case, as well as comparative analysis of the previously described cases, are of high practical value.

\section{References}

1. Zhou JY, Xu B, Lopes J, Blamoun J, Li L (2017) Hashimoto encephalopathy: literature review. Acta Neurol Scand 135: 285-290.

2. Sunil GS, Mariash CN (2001) Hashimoto's encephalitis. J Clin Endocrinol Metab 86: 947.

3. Chong JY, Rowland LP, Utiger RD (2003) Hashimoto encephalopathy: syndrome or myth? Arch Neurol 60: 164-171.

4. Yu HJ, Lee J, Seo DW, Lee M (2014) Clinical manifestations and treatment response of steroid in pediatric Hashimoto encephalopathy. J Child Neurol 29: 938-942.

5. Peschen-Rosin R, Schabet M, Dichgans J (1999) Manifestation of Hashimoto's encephalopathy years before onset of thyroid disease. Eur Neurol 41: 79-84.

6. Tang $Y$, Xing $Y$, Lin MT, Zhang J, Jia J (2012) Hashimoto's encephalopathy cases: Chinese experience. BMC Neurol 12: 60.

7. Mocellin R, Walterfang M, Velakoulis D (2007) Hashimoto's encephalopathy: epidemiology, pathogenesis and management. CNS Drugs 21: 799-811.

8. Kothbauer-Margreiter I, Sturzenegger M, Komor J, Baumgartner R, Hess CW (1996) Encephalopathy associated with Hashimoto thyroiditis: diagnosis and treatment. J Neurol 243: 585-593.

9. Ferracci F, Bertiato G, Moretto G (2004) Hashimoto's encephalopathy: epidemiologic data and pathogenetic considerations. J Neurol Sci 217: 165-168.

10. Chaudhuri A, Behan PO (2003) The clinical spectrum, diagnosis, pathogenesis and treatment of Hashimoto's encephalopathy (recurrent acute disseminated encephalomyelitis). Curr Med Chem 10: 1945-1953.

11. Ferracci F, Carnevale A (2006) The neurological disorder associated with thyroid autoimmunity. J Neurol 253: 975-984.
12. Caselli RJ, Boeve BF, Scheithauer BW, O'Duffy JD, Hunder GG (1999) Nonvasculitic autoimmune inflammatory meningoencephalitis (NAIM): a reversible form of encephalopathy. Neurology 53: 15791581.

13. Sadan O, Seyman E, Ash EL, Kipervasser S, Neufeld MY (2013) Adultonset temporal lobe epilepsy, cognitive decline, multi-antiepileptic drug hypersensitivity, and Hashimoto's encephalopathy: Two case studies. Epilepsy Behav Case Rep 1: 132-135.

14. Nolte KW, Unbehaun A, Sieker H, Kloss TM, Paulus W (2000) Hashimoto encephalopathy: a brainstem vasculitis? Neurology 54 : 769-770.

15. Duffey P, Yee S, Reid IN, Bridges LR (2003) Hashimoto's encephalopathy: postmortem findings after fatal status epilepticus. Neurology 61: 1124-1126.

16. Forchetti CM, Katsamakis G, Garron DC (1997) Autoimmune thyroiditis and a rapidly progressive dementia: global hypoperfusion on SPECT scanning suggests a possible mechanism. Neurology 49: 623-626.

17. Cao NJ, Tselis AC, Li J, Gorman M (2005) A case of Hashimoto's encephalopathy: association with sensory ganglionopathy. J Neurol Sci 238: 105-107.

18. Drulović J, Andrejević S, Bonaci-Nikolić B, Mijailović V (2011) Hashimoto's encephalopathy: a long-lasting remission induced by intravenous immunoglobulins. Vojnosanit Pregl 68: 452-454.

19. Erol I, Saygi S, Alehan F (2011) Hashimoto's encephalopathy in children and adolescents. Pediatr Neurol 45: 420-422.

20. Selim M, Drachman D (2001) Ataxia associated with Hashimoto's disease: progressive non-familial adult onset cerebellar degeneration with autoimmune thyroiditis. I Neurol Neurosurg Psychiatry 71: 81-87.

21. Sheng B, Lau KK, Li HL, Cheng LF (2005) A case of Hashimoto's encephalopathy with demyelinating peripheral neuropathy. Eur Neurol 53: 84-85.

22. Juraj Payer, Tomas Petrovic, Lubomir Lisy, Pavel Langer (2012) Hashimoto Encephalopathy: A Rare Intricate Syndrome. Int J Endocrinol Metab 10: 506-514.

23. Oide T, Tokuda T, Yazaki M, Watarai M, Mitsuhashi S, et al. (2004) Anti-neuronal autoantibody in Hashimoto's encephalopathy: neuropathological, immunohistochemical, and biochemical analysis of two patients. J Neurol Sci 217: 7-12.

24. Nakagawa H, Yoneda M, Fujii A, Kinomoto K, Kuriyama M (2007) Hashimoto's encephalopathy presenting with progressive cerebellar ataxia. J Neurol Neurosurg Psychiatry 78: 196-197.

25. Mahmud FH, Lteif AN, Renaud DL, Reed AM, Brands CK (2003) Steroid-responsive encephalopathy associated with Hashimoto's thyroiditis in an adolescent with chronic hallucinations and depression: case report and review. Pediatrics 112: 686-690.

26. Taurin G, Golfier V, Pinel JF, Deburghgraeve V, Poirier JY, et al. (2002) Choreic syndrome due to Hashimoto's encephalopathy. Mov Disord 17: 1091-1092.

27. Boers P, Colebatch J (2001) Hashimoto's encephalopathy responding to plasmapheresis. J Neurol Neurosurg Psychiatry 70: 132.

28. Cantón A, de Fàbregas O, Tintoré M, Mesa J, Codina A, et al. (2000) Encephalopathy associated to autoimmune thyroid disease: a more appropriate term for an underestimated condition? J Neurol Sci 176: 65-69.

Citation: Zvonarev V, Tregubenko P (2020) Hashimoto Encephalopathy: Advanced Review of Clinical and Scientific Aspects. J Neurol Neurobiol 
29. Ferracci F, Moretto G, Candeago RM, Cimini N, Conte F, et al. (2003) Antithyroid antibodies in the CSF: their role in the pathogenesis of Hashimoto's encephalopathy. Neurology 60: 712-714.

30. Spiegel J, Hellwig D, Becker G, Müller M (2004) Progressive dementia caused by Hashimoto's encephalopathy -- report of two cases. Eur J Neurol 11: 711-713.

31. Lagström RMB, Østerbye NN, Henriksen OM, Høgh P (2019) Hashimoto's encephalopathy: Follow-up data from neuropsychology, lumbar puncture, and FDG-PET. Clin Case Rep 7: 1750-1753.

32. Sharma SR, Sharma N, Roy D (2018) Hashimoto's encephalopathy in a pregnant female: A diagnosis in disguise. Ind Psychiatry $\mathrm{J} 27$ 302-304.

33. Ferlazzo E, Raffaele M, Mazzù I, Pisani F (2006) Recurrent status epilepticus as the main feature of Hashimoto's encephalopathy. Epilepsy Behav 8: 328-330.

34. Rodriguez AJ, Jicha GA, Steeves TD, Benarroch EE, Westmoreland BF (2006) EEG changes in a patient with steroid-responsive encephalopathy associated with antibodies to thyroperoxidase (SREAT, Hashimoto's encephalopathy). J Clin Neurophysiol 23: 371 373.

35. Termsarasab P, Pitakpatapee Y, Frucht SJ, Srivanitchapoom P (2018) Steroid-responsive Encephalopathy Associated with Autoimmune Thyroiditis (SREAT) Presenting with Pure Cerebellar Ataxia. Tremor Other Hyperkinet Mov (N Y) 8: 585.

36. Liu CY, Tseng MC, Lin PH (2011) Encephalopathy associated with autoimmune thyroid disease (Hashimoto's thyroiditis) presenting as depression: a case report. Gen Hosp Psychiatry 33: 641.e7-641.e9.

37. Hajnal L, Lazary J (2019) Cotard-syndrome associated with Hashimoto encephalopathy: a case report. Neuropsychopharmacol Hung 21: 85-93.

38. Kastrup O, Maschke M, Schlamann K, Diener HC (2005) Hashimoto encephalopathy and neuralgic amyotrophy--causal link or chance association? Eur Neurol 53: 98-99.

39. Liu S, Ma Q, Zheng Y (2019) Febrile Hashimoto's encephalopathy associated with Graves' disease and acute pancytopenia: A case report. Medicine (Baltimore) 98: e18012.

40. Gayatri NA, Whitehouse WP (2005) Pilot survey of Hashimoto's encephalopathy in children. Dev Med Child Neurol 47: 556-558.

41. Cook MK, Malkin M, Karafin MS (2015) The use of plasma exchange in Hashimoto's encephalopathy: A case report and review of the literature. J Clin Apher 30: 188-192.

42. Matsunaga A, Ikawa M, Kawamura Y, Kishitani T, Yamamura O, et al. (2019) Serial brain MRI changes related to autoimmune pathophysiology in Hashimoto encephalopathy with anti-NAE antibodies: A case-series study. J Neurol Sci 406: 116453.

43. Nieuwenhuis L, Santens P, Vanwalleghem P, Boon P (2004) Subacute Hashimoto's encephalopathy, treated with plasmapheresis. Acta Neurol Belg 104: 80-83.

44. de Cerqueira AC, Bezerra JM, de Magalhães GC, Rozenthal M, Nardi AE (2008) Hashimoto's encephalopathy with clinical features similar to those of Creutzfeldt-Jakob disease. Arq Neuropsiquiatr 66: 903 905

45. Henchey R, Cibula J, Helveston W, Malone J, Gilmore RL (1995) Electroencephalographic findings in Hashimoto's encephalopathy. Neurology 45: 977-981.

46. Fujii A, Yoneda M, Ito T, Yamamura O, Satomi S, et al. (2005) Autoantibodies against the amino terminal of alpha-enolase are a useful diagnostic marker of Hashimoto's encephalopathy. J Neuroimmunol 162: 130-136.

47. Vander T, Hallevy C, Alsaed I, Valdman S, Ifergane G, et al. (2004) 143-3 protein in the CSF of a patient with Hashimoto's encephalopathy. J Neurol 251: 1273-1274.

48. Frank Leypoldt, Thaís Armangue, Josep Dalmau (2015) Autoimmune encephalopathies. Ann N Y Acad Sci 1338: 94-114.

49. Vernino S, Geschwind M, Boeve B (2007) Autoimmune encephalopathies. Neurologist 13: 140-147.

50. Vasconcellos E, Piña-Garza JE, Fakhoury T, Fenichel GM (1999) Pediatric manifestations of Hashimoto's encephalopathy. Pediatr Neurol 20: 394-398.

51. Marshall GA, Doyle JJ (2006) Long-term treatment of Hashimoto's encephalopathy. J Neuropsychiatry Clin Neurosci 18: 14-20.

52. Olmez I, Moses H, Sriram S, Kirshner H, Lagrange AH, et al. (2013) Diagnostic and therapeutic aspects of Hashimoto's encephalopathy. J Neurol Sci 331: 67-71.

53. Mattozzi S, Sabater L, Escudero D, Ariño H, Armangue T, et al. (2020) Hashimoto encephalopathy in the $21^{\text {st }}$ century. Neurology 94 : e217-e224.

54. Nagpal T, Pande S (2004) Hashimoto's encephalopathy: Response to plasma exchange. Neurol India 52: 245-247.

55. Sharma PM, Javali M, Mahale R, Madhusudhan BK, Majeed AA, et al. (2015) Hashimoto encephalopathy: A study of the clinical profile, radiological and electrophysiological correlation in a Tertiary Care Center in South India. J Neurosci Rural Pract 6: 309-314.

56. Kon Chu (2016) Effect of Erythropoietin in Refractory Autoimmune Encephalitis Patients. ClinicalTrials.gov. 